\title{
KAMUS DIGITAL TANAMAN OBAT MENGGUNAKAN ALGORITMA ROCCHIO BERBASIS MOBILE
}

\author{
Arie Qur'ania'), Triastinurmiatiningsih ${ }^{2)}$, Nazar Muhamad Ikhbal ${ }^{3)}$ \\ $\left.{ }^{1,3}\right)$ Program Studi IImu Komputer, ${ }^{2}$ )Program Studi Biologi, FMIPA, \\ Universitas Pakuan, Bogor, Indonesia \\ Corresponding Author: qurania@unpak.ac.id
}

\begin{abstract}
Abstrak
Kamus digital sudah banyak digunakan untuk memudahkan dalam pengolahan kata dan pencarian kata melalui media digital seperti handphone. Masyarakat umumnya mengetahui khasiat dan cara meracik tanaman obat dari pengalaman orang tua terdahulu atau melalui buku dan tulisan. Penelusuran melalui buku atau tulisan memerlukan waktu yang tidak singkat dibandingkan dengan penelusuran melalui media digital salah satunya adalah kamus digital. Penelitian bertujuan untuk membuat kamus digital tanaman obat berbasis mobile yang memiliki fasilitas pencarian berdasarkan kata yang diinputkan misalnya kandungan yang dimiliki oleh tanaman obat. Aplikasi kamus digital tanaman obat menggunakan metode pencarian dengan algoritma Rocchio dengan teknik relevance feedback untuk mengecek kedekatan query ke rataan dokumen relevan dengan tingkat perhitungan similaritas melalui tahapan tokenizing, filtering, stemming, dan Term Weighting dengan jumlah data sebanyak 200 tanaman obat.
\end{abstract}

Kata kunci: kamus digital, tanaman obat, algoritma Rocchio

\begin{abstract}
Digital dictionaries have been widely used to facilitate word processing and word search through digital media such as mobile phones. Society generally knows the efficacy and how to mix medicinal plants from the experience of previous parents or through books and writings. Searching through books or writings requires a short time compared to searching through digital media, one of which is a digital dictionary. The research aims to create a digital dictionary of mobile-based medicinal plants which has a search facility based on the words entered, for example, the contents of the medicinal plants. The digital dictionary application of medicinal plants uses a search method with the Rocchio algorithm with relevance feedback techniques to check the proximity of the query to the average document relevant to the level of similarity calculation through the stages of tokenizing, filtering, stemming, and Term Weighting with a total data of 200 medicinal plants.
\end{abstract}

Keywords: digital dictionary, plant feeds, algorithm Rocchio

\section{Pendahuluan}

Tanaman Obat di Indonesia digunakan dan dimanfaatkan secara luas sebagai pengobatan herbal, bahan jamu-jamuan, makan penguat daya tahan tubuh, produk kecantikan (kosmetik dan spa serta sebagai bahan baku industri makanan dan minuman. Di Indonesia, volume perdagangan obat tradisional tahun 2002 baru mencapai 150 juta dolar. Lebih dari $61 \%$ penduduk Indonesia sudah terbiasa mengkonsumsi obat tradisional, misalnya jamu. Sementara itu, kebutuhan bahan baku untuk perusahaan obat tradisional baik industri besar maupun kecil sebagian besar (85\%) berasal dari hasil hutan dan pekarangan tanpa upaya budi daya (IPB Magazine, 2015)[1]. Penelitian mengenai tanaman obat sudah dilakukan oleh peneliti bersama tim pada tahun 2014 tentang identifikasi tanaman obat menggunakan citra daun dengan teknik kode fraktal [2], yang merupakan pengembangan penelitian sebelumnya yang menggunakan dimensi fraktral pada tahun 2012 [3]. Penelitian tersebut belum sampai pada khasiat dan penggunaan tanaman obat. Selama ini untuk pencarian informasi tentang khasiat tanaman obat masih menggunakan manual, yaitu dengan pencarian menggunakan buku atau literatur, hal ini 
memerlukan waktu pencarian yang tidak singkat. Di era digital dengan kemajuan peralatan komputer, diperlukan sebuah aplikasi berbasis mobile yang dapat membantu masyarakat dalam mencari informasi hanya dengan proses yang cepat dan akurasi yang tinggi sesuai dengan apa yang dicari pengguna.

Penelitian ini bertujuan untuk membuat kamus digital tentang khasiat tanaman obat berbasis mobile yang memiliki fasilitas pencarian berdasarkan kata kunci penyakit atau nama tanaman obat. Di era mobile yang semakin pesat, informasi terkait tentang khasiat tanaman obat dikembangkan dalam bentuk aplikasi yang memudahkan masyarakat umum mencari manfaat serta cara penggunaan tanaman obat untuk mengobati penyakit dengan bahan alami. Aplikasi kamus khasiat tanaman obat dibangun dengan bantuan komputer yang diprogram menggunakan algoritma pencarian Rocchio yang akan mencari berdasarkan data yang sudah diinputkan ke dalam sistem database. Output berupa detail nama tanaman dan khasiat serta cara penggunaan dan bagian mana dari tanaman yang dapat dimanfaatkan untuk mengobati penyakit. Algoritma Rocchio digunakan dalam teknik pencarian data didasarkan pada kemampuan umpan balik relevansi menggunakan Vector Space Model yang didasarkan pada asumsi bahwa pengguna dalam pencarian data memiliki konsep umum tentang dokumen mana yang bisa dinyatakan relevan atau tidak relevan [5].

Penelitian yang berkaitan dengan pengembangan metode Rocchio diantaranya Najib, 2018 [4] menghasilkan Similaritas Dokumen Tugas Akhir Menggunakan Metode Rocchio sebuah metode yang dapat digunakan untuk membandingkan dokumen terhadap kesamaan isi antara data dengan merepresentasikan semua data dalam sebuah vector suatu term (istilah kata). Rocchio memiliki konsep umum pada dokumen yang relevan dan non-relevan sebagai sarana meningkatkan pencarian untuk mengetahui kemiripan dokumen dengan dokumen lainnya. Kristanda, 2017 [5] menghasilkan Rancang Bangun Aplikasi UMN Library Catalog Menggunakan Metode Rocchio Relevance Feedback menunjukkan bahwa pencarian buku di SLiMS UMN termasuk mudah untuk dilakukan dan mudah untuk dipelajari. SliMS yang merupakan sistem informasi berbasis web ini juga berpotensi untuk didukung dengan aplikasi mobile dalam melakukan pencarian buku. Hal ini diperkuat dengan hasil survey terhadap ketertarikan responden dalam melakukan pencarian buku lewat smartphone.

\section{Metode Penelitian}

Tahap awal penelitian adalah dengan pengumpulan data tentang tanaman obat sebanyak 200 data tanaman obat. Data gambar dan khasiat tanaman obat yang sudah diinput akan difilter atribut sesuai dengan kata kunci yang biasa diinputkan untuk pencarian khasiat tanaman obat. Proses pencocokan kata kunci dan data tanaman obat akan diproses dalam tahap tokenizing, filtering, stemming, dan term weighting. Aplikasi kamus digital akan dipersiapkan bersamaan dengan proses input data ke database. Algoritma pencarian dengan Rocchio akan disusun untuk bisa membandingkan antara kata kunci yang diinput pada aplikasi dengan dokumen yang memiliki kemiripan tertinggi. Proses selanjutnya adalah proses filter data tanaman obat yang berelasi dengan kata kunci yang diinput. Hasil filter data tanaman obat akan dimunculkan sebagai output dari hasil pencarian. Tahapan penelitian ditunjukkan pada Gambar 1. 


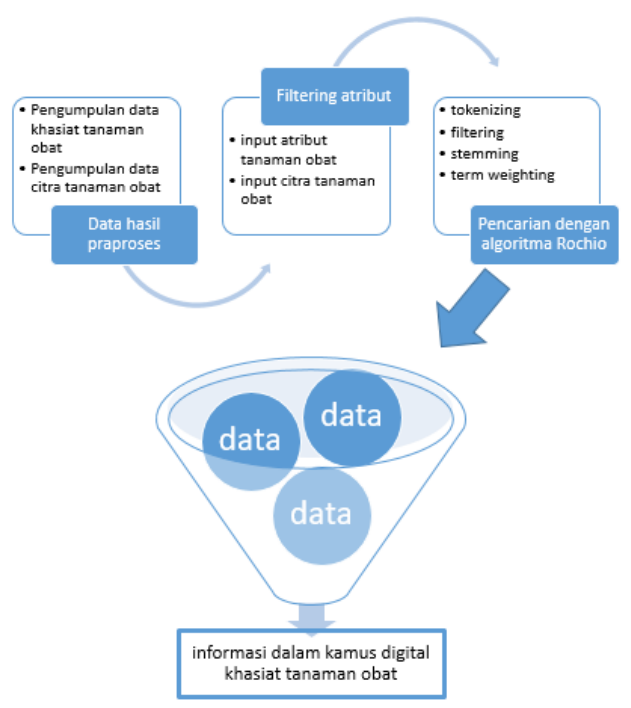

Gambar 1. Tahapan Penelitian

\subsection{Tanaman obat}

Tanaman obat menurut Hariana, 2008 [6] merupakan tanaman yang memiliki khasiat obat untuk pencegahan dan menyembuhan penyakit. Tanaman obat yang tumbuh dan dibudidayakan di Indonesia dan digunakan secara turun temurun untuk tujuan kesehatan disebut herbal asli Indonesia, menurut peraturan menteri kesehatan RI no 6 tahun 2016 [7]. Tanaman obat atau biofarmaka didefinisikan sebagai jenis tanaman yang sebagian, seluruh tanaman dan atau eksudat tanaman tersebut digunakan sebagai obat, bahan atau ramuan obat-obatan. Eksudat tanaman adalah isi sel yang secara spontan keluar dari tanaman atau dengan cara tertentu sengaja dikeluarkan dari selnya. Eksudat tanaman dapat berupa zat-zat atau bahan-bahan nabati lainnya yang dengan cara tertentu dipisahkan/diisolasi tanamannya menurut Herdiani, 2012 [8]. Tanaman obat potensial adalah tanaman yang diduga mengandung atau memiliki senyawa aktif berkhasiat obat tetapi belum dibuktikan penggunaannya secara ilmiah-medis sebagai bahan obat-obatan. Contoh buah mengkudu dan temu kunci [9].

\subsection{Kamus Digital}

Kamus digital adalah kamus yang lebih mengutamakan pada fasilitas pengolah kata elektronis, yaitu sebuah fasilitas yang memungkinkan aplikasi pengolah kata memeriksa ejaan dari dokumen yang diketik. Pengguna kamus elektronis atau kamus digital dalam aplikasi pemrosesan teks merupakan hal yang tidak dapat dihindarkan. Kamus merupakan basis pemeriksaan, basis pengetahuan, bahkan sebagai basis penyelidikan [10].

\subsection{Algoritma Rocchio}

Pencarian dengan algoritma Rocchio merupakan teknik Metode rocchio relevance feedback adalah strategi reformulasi query yang digunakan untuk membantu user pemula dalam information retrieval systems. User disajikan dengan hasil pencarian dokumen yang relevan [11]. Information retrieval atau document retrieval adalah teknik untuk menghasilkan hasil dokumen relevan dengan request dari user melalui perbandingan request dengan indeks yang menghasilkan tingkat similarity dari konten yang dipilih [12]. Teknik relevance feedback digunakan setelah user memasukkan keyword yang data sudah didapat dari pencarian di database. Relevance feedback mendekatkan query ke rataan dokumen relevan dengan tingkat perhitungan similaritas [13]. Berikut tahapan perhitungan metode Rocchio.

a. Tokenizing adalah tahap pemrosesan sebuah kata kunci menjadi unit kecil. Pembuatan token dilakukan pada kata kunci dan dokumen yang didapat.

b. Filtering adalah tahap mengambil kata-kata penting dari hasil tokenizing. Tahap ini katakata yang tidak deskriptif dibuang, seperti kata "yang", "dan", "di". 
c. Stemming adalah tahap mencari akar kata sesuai dengan kata kunci. Tahap ini dilakukan proses pengembalian berbagai kata ke dalam suatu representasi.

d. Term Weighting adalah tahap pembobotan tiap term yang dicari pada setiap dokumen sehingga dapat diketahui ketersediaan dan kemiripan suatu term dalam dokumen. Perhitungan term frequency dan inverse document frequency akan dilakukan bersamaan dengan query yang merupakan fitur di dalam database. Term frequency (tf) adalah frekuensi dari kemunculan sebuah term dalam dokumen yang bersangkutan. Inverse document frequency (idf) merupakan sebuah perhitungan dari bagaimana term didistribusikan secara luas pada koleksi dokumen yang bersangkutan. Rumusan nilai idf sebuah term dapat dijabarkan menjadi persamaan berikut [14].

$$
i d f=\log \frac{n}{d f}
$$

keterangan:

idf : nilai inverse document frequency.

$\mathrm{N}$ : jumlah dokumen di dalam koleksi.

Df : nilai document frequency.

Jika pencarian pada dokumen yang cukup besar, skema yang dapat digunakan untuk pemberian bobot adalah term frequency dikalikan dengan inverse document frequency yang disebut sebagai nilai bobot term atau $\beta$ [13].

Keterangan:

$$
\beta=(t f)^{*} i d f
$$

$\beta$ : nilai bobot term.

Tf: nilai term frequency.

Idf: nilai inverse document frequency.

Selanjutnya, tingkat kemiripan term dengan judul dokumen akan dimasukkan ke dalam sebuah fungsi perhitungan similaritas yaitu metode Rocchio yang dapat dilihat dari rumusan manual sebagai berikut [13].

Keterangan:

$$
R=N+\beta\left(\left(\frac{D p}{N p}\right)-\left(\frac{D n}{N n}\right)\right)
$$

$\mathrm{R}$ : tingkat kemiripan term.

$\mathrm{N}$ : jumlah term tiap dokumen.

$\beta$ : nilai bobot term.

$\mathrm{Dp}$ : term dari dokumen relevan.

$\mathrm{Np}$ : jumlah term keseluruhan dokumen relevan.

Dn : term dari dokumen tidak relevan.

$\mathrm{Nn}$ : jumlah term keseluruhan dokumen tidak relevan

\section{Hasil dan Pembahasan}

Algoritma Rocchio melibatkan suatu query yang diproses menjadi sebuah vektor space yang dapat dibandingkan dengan masing-masing centroid kelas yang ada pada korpus. Pendekatan dilakukan dengan mencari kemiripan dua vektor space, vektor query dianggap mirip dengan sebuah centroid kelas menggunakan jarak (distance) atau menggunakan kemiripan (similarity). Jika menggunakan jarak, yang dicari adalah kelas yang memiliki jarak yang terkecil dengan query. Tahapan penerapan algoritma Rocchio seperti contoh berikut :

\subsection{Contoh Penerapan Algortima Rocchio}

Proses awal dengan pencarian kata pada Query : Glukosa pada 3 dokumen, proses tokenizing, filtering, dan stemming ditunjukkan pada Tabel 1.

Tabel 1. Tahapan tokenizing, filtering, dan stemming pada dokumen

\begin{tabular}{cllll}
\hline No & Isi Dokumen & Tokenizing & Filtering & Stemming \\
\hline 1 & Glukosida dan & Glukosida dan & Glukosida dan urai & Glukosida dan urai \\
& terurai menjadi & terurai menjadi & jadi Glukosa dan & jadi Glukosa dan \\
& Glukosa dan & Glukosa dan & Aglukon Glukosida & Aglukon Glukosida \\
& Aglukon Glukosida & Aglukon Glukosida & penting yaitu & penting yaitu \\
\hline
\end{tabular}




\begin{tabular}{|c|c|c|c|c|}
\hline & $\begin{array}{l}\text { terpenting yaitu : } \\
\text { Purpureaglukosida } \\
\text { A : Digitoksina : } \\
\text { Digitoksigenina + } 3 \\
\text { Digitoksosa + } \\
\text { Glukosa } \\
\text { Purpureaglukosida } \\
\text { B : Gitoksina } \\
\text { Gitoksigenina + } 3 \\
\text { Digitoksosa + } \\
\text { Glukosa } \\
\text { Purpureaglukosida } \\
\text { C: Gitalina: } \\
\text { Gitaligenina + } 3 \\
\text { Digitoksosa } \\
\text { Kardiatonika }\end{array}$ & $\begin{array}{l}\text { terpenting yaitu } \\
\text { Purpureaglukosida } \\
\text { A Digitoksina } \\
\text { Digitoksigenina + } 3 \\
\text { Digitoksosa + } \\
\text { Glukosa } \\
\text { Purpureaglukosida } \\
\text { B Gitoksina } \\
\text { Gitoksigenina + } 3 \\
\text { Digitoksosa + } \\
\text { Glukosa } \\
\text { Purpureaglukosida } \\
\text { C Gitalina } \\
\text { Gitaligenina + } 3 \\
\text { Digitoksosa } \\
\text { Kardiatonika }\end{array}$ & $\begin{array}{l}\text { Purpureaglukosida } \\
\text { A Digitoksina } \\
\text { Digitoksigenina + } 3 \\
\text { Digitoksosa + } \\
\text { Glukosa } \\
\text { Purpureaglukosida } \\
\text { B Gitoksina } \\
\text { Gitoksigenina + } 3 \\
\text { Digitoksosa + } \\
\text { Glukosa } \\
\text { Purpureaglukosida } \\
\text { C Gitalina } \\
\text { Gitaligenina + } 3 \\
\text { Digitoksosa } \\
\text { Kardiatonika }\end{array}$ & $\begin{array}{l}\text { Purpureaglukosida } \\
\text { A Digitoksina } \\
\text { Digitoksigenina + } 3 \\
\text { Digitoksosa + } \\
\text { Glukosa } \\
\text { Purpureaglukosida } \\
\text { B Gitoksina } \\
\text { Gitoksigenina + } 3 \\
\text { Digitoksosa + } \\
\text { Glukosa } \\
\text { Purpureaglukosida } \\
\text { C Gitalina } \\
\text { Gitaligenina + } 3 \\
\text { Digitoksosa } \\
\text { Kardiatonika }\end{array}$ \\
\hline 2 & $\begin{array}{l}\text { Glukosida- } \\
\text { glukosida terdiri } \\
\text { dari } 5 \text { golongan : a. } \\
\text { Digitoksigenina : } \\
\text { lanatosida b. } \\
\text { Gitoksigenina : } \\
\text { lanatosida B c. } \\
\text { Digoksigenina : } \\
\text { Digoksina d. } \\
\text { Diginatigenina : } \\
\text { Diginatika e. } \\
\text { Gitaloksigenina : } \\
\text { Gitaloksina Isolasi } \\
\text { Glukosa terutama } \\
\text { Digoksina }\end{array}$ & $\begin{array}{l}\text { Glukosida- } \\
\text { glukosida terdiri } \\
\text { dari } 5 \text { golongan a } \\
\text { Digitoksigenina } \\
\text { lanatosida b } \\
\text { Gitoksigenina } \\
\text { lanatosida B c } \\
\text { Digoksigenina } \\
\text { Digoksina d } \\
\text { Diginatigenina } \\
\text { Diginatika e } \\
\text { Gitaloksigenina } \\
\text { Gitaloksina Isolasi } \\
\text { Glukosa terutama } \\
\text { Digoksina }\end{array}$ & $\begin{array}{l}\text { Glukosida- } \\
\text { glukosida diri dari } 5 \\
\text { golong a } \\
\text { Digitoksigenina } \\
\text { lanatosida b } \\
\text { Gitoksigenina } \\
\text { lanatosida B c } \\
\text { Digoksigenina } \\
\text { Digoksina d } \\
\text { Diginatigenina } \\
\text { Diginatika e } \\
\text { Gitaloksigenina } \\
\text { Gitaloksina Isolasi } \\
\text { Glukosa utama } \\
\text { Digoksina }\end{array}$ & $\begin{array}{l}\text { Glukosida- } \\
\text { glukosida diri dari } 5 \\
\text { golong a } \\
\text { Digitoksigenina } \\
\text { lanatosida b } \\
\text { Gitoksigenina } \\
\text { lanatosida B c } \\
\text { Digoksigenina } \\
\text { Digoksina d } \\
\text { Diginatigenina } \\
\text { Diginatika e } \\
\text { Gitaloksigenina } \\
\text { Gitaloksina Isolasi } \\
\text { Glukosa utama } \\
\text { Digoksina }\end{array}$ \\
\hline 3 & $\begin{array}{l}\text { Glukosa dan } \\
\text { dammar, hidrat } \\
\text { arang, } \\
\text { tannin,garam, } \\
\text { alkali Anti diare, } \\
\text { adstringen }\end{array}$ & $\begin{array}{l}\text { Glukosa dan } \\
\text { dammar hidrat } \\
\text { arang tanningaram } \\
\text { alkali Anti diare } \\
\text { adstringen }\end{array}$ & $\begin{array}{l}\text { Glukosa dan } \\
\text { dammar hidrat } \\
\text { arang tanningaram } \\
\text { alkali Anti diare } \\
\text { adstringen }\end{array}$ & $\begin{array}{l}\text { Glukosa dan } \\
\text { dammar hidrat } \\
\text { arang tanningaram } \\
\text { alkali Anti diare } \\
\text { adstringen }\end{array}$ \\
\hline
\end{tabular}

Tabel 1 menunjukkan pada proses tokenizing menghilangkan tanda baca seperti tanda koma, titik dua, dan titik, pada proses filtering menghilangkan awalan dan akhiran seperti pada kata terurai menjadi kata urai, sedangkan pada proses stemming proses pengembalian berbagai kata ke dalam suatu representasi, pada kasus ini hasil pada proses filtering sama dengan hasil stemming.

Hasil proses Rocchio selengkapnya ditunjukan pada Gambar 2 dengan contoh Query yang diinput 'Glukosa' maka akan terkumpul dokumen-dokumen yang mengandung kata 'Glukosa'. 


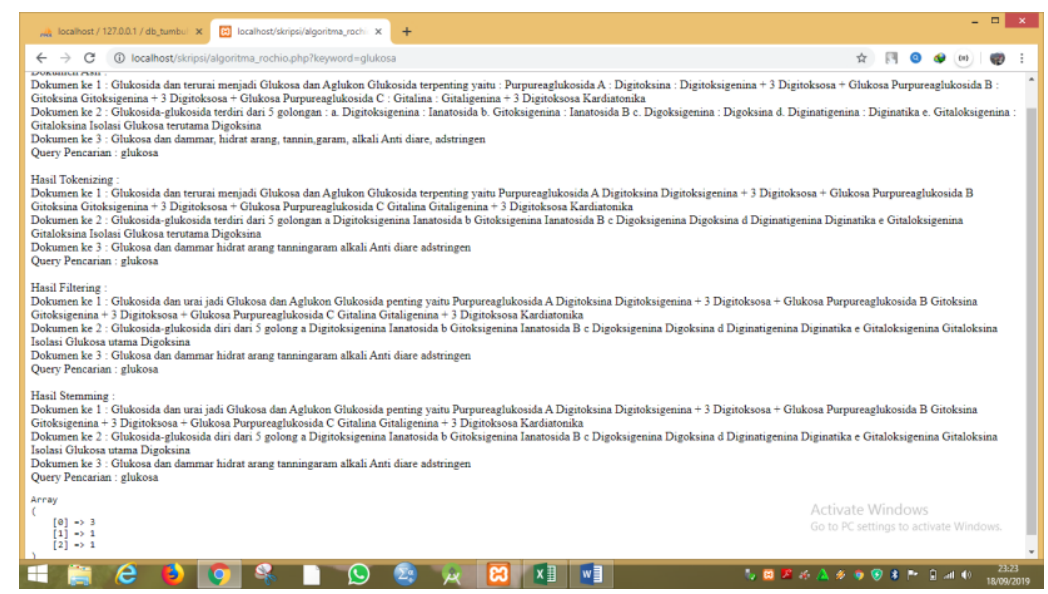

Gambar 2. Penerapan algoritma Rocchio

Proses perhitungan untuk mendapatkan nilai Tf-Idf ditunjukkan pada Tabel 2, sedangkan hasil perhitungan jarak ditunjukkan pada Tabel 3.

Tabel 2. Contoh hasil perhitungan Tf-ldf

\begin{tabular}{|c|c|c|c|c|c|c|c|c|c|c|c|}
\hline \multirow[t]{2}{*}{ Term } & \multicolumn{4}{|c|}{ TF } & \multirow[t]{2}{*}{$\mathrm{df}$} & \multirow[t]{2}{*}{$\mathrm{D} / \mathrm{df}$} & \multirow{2}{*}{$\begin{array}{l}\text { Log } \\
\text { (D/df) }\end{array}$} & \multicolumn{4}{|c|}{ w } \\
\hline & Q & D1 & $\mathrm{D} 2$ & D3 & & & & Q & D1 & D2 & D3 \\
\hline Glukosida & 0 & 1 & 2 & 0 & 3 & 1 & 0 & 0 & 0 & 0 & 0 \\
\hline Glukosa & 1 & 3 & 1 & 1 & 5 & 0,6 & 0,221 & 0,221 & 0,221 & 0,221 & 0,221 \\
\hline Aglukon & 0 & 1 & 0 & 0 & 1 & 3 & 0,477 & 0 & 0,477 & 0 & 0 \\
\hline Purpureaglukosida & 0 & 3 & 0 & 0 & 3 & 1 & 0 & 0 & 0 & 0 & 0 \\
\hline Digitoksina & 0 & 1 & 0 & 0 & 1 & 3 & 0,477 & 0 & 0.477 & 0 & 0 \\
\hline Digitoksigenina & 0 & 1 & 1 & 0 & 2 & 1,5 & 0,176 & 0 & 0,176 & 0,176 & 0 \\
\hline Diigitoksosa & 0 & 3 & 0 & 0 & 3 & 1 & 0 & 0 & 0 & 0 & 0 \\
\hline Gitalina & 0 & 1 & 0 & 0 & 1 & 3 & 0,477 & 0 & 0,477 & 0 & 0 \\
\hline Gitaligenina & 0 & 1 & 0 & 0 & 1 & 3 & 0,477 & 0 & 0,477 & 0 & 0 \\
\hline Kardiatonika & 0 & 1 & 0 & 0 & 1 & 3 & 0,477 & 0 & 0,477 & 0 & 0 \\
\hline lanatosida & 0 & 1 & 1 & 0 & 2 & 1,5 & 0,176 & 0 & 0,176 & 0.176 & 0 \\
\hline Digoksina & 0 & 0 & 1 & 0 & 1 & 3 & 0,477 & 0 & 0 & 0.477 & 0 \\
\hline Isolasi & 0 & 0 & 1 & 0 & 1 & 3 & 0,477 & 0 & 0 & 0.477 & 0 \\
\hline Dammar & 0 & 0 & 0 & 1 & 1 & 3 & 0,477 & 0 & 0 & 0 & 0.477 \\
\hline Hidrat & 0 & 0 & 0 & 1 & 1 & 3 & 0,477 & 0 & 0 & 0 & 0.477 \\
\hline Arang & 0 & 0 & 0 & 1 & 1 & 3 & 0,477 & 0 & 0 & 0 & 0.477 \\
\hline Alkari & 0 & 0 & 0 & 1 & 1 & 3 & 0,477 & 0 & 0 & 0 & 0.477 \\
\hline
\end{tabular}

Tabel 2 menunjukkan jumlah term pada dokumen 1, 2, dan 3 (D1, D2, D3), misalnya kata 'Glukosa' pada D1 ditemukan sebanyak 3, pada D2 sebanyak 1, dan pada D3 sebanyak 1. Proses selanjutnya menghitung nilai bobot $(w)$ yang akan menghitung kedekatan dengan nilai bobot pada Query (Q), dalam kasus ini nilai w pada term 'Glukosa' menghasilkan nilai yang sama yaitu 0,221.

Hasil nilai w pada Tabel 2 digunakan untuk menghitung panjang vektor pada term yang dicari, pada kasus ini term 'Glukosa' memiliki jarak terdekat sebesar 0,05 jika dibandingkan dengan nilai pada term yang lain. Hasil perhitungan seperti ditunjukkan pada Tabel 3.

Tabel 3. Menghitung jarak dan Query

\begin{tabular}{|c|c|c|c|c|c|c|c|}
\hline \multirow[t]{2}{*}{ Term } & \multicolumn{3}{|c|}{$\mathrm{W}(\mathrm{Q})^{\star} \mathrm{W}(\mathrm{Di})$} & \multicolumn{4}{|c|}{ Panjang Vektor } \\
\hline & D1 & D2 & D3 & $Q^{\wedge} 2$ & $\mathrm{D} 1^{\wedge} 2$ & $\mathrm{D} 2^{\wedge} 2$ & $\mathrm{D}^{\wedge} 2$ \\
\hline Glukosida & 0 & 0 & 0 & 0 & 0 & 0 & 0 \\
\hline Glukosa & 0.05 & 0.05 & 0.05 & 0.05 & 0.05 & 0.05 & 0.05 \\
\hline Aglukon & 0 & 0 & 0 & 0 & 0.227 & 0 & 0 \\
\hline Purpureaglukosida & 0 & 0 & 0 & 0 & 0 & 0 & 0 \\
\hline Digitoksina & 0 & 0 & 0 & 0 & 0.277 & 0 & 0 \\
\hline
\end{tabular}




\begin{tabular}{lrrrrrrr}
\hline Digitoksigenina & 0 & 0 & 0 & 0 & 0.031 & 0.031 & 0 \\
\hline Diigitoksosa & 0 & 0 & 0 & 0 & 0 & 0 & 0 \\
\hline Gitalina & 0 & 0 & 0 & 0 & 0.277 & 0 & 0 \\
\hline Gitaligenina & 0 & 0 & 0 & 0 & 0.277 & 0 & 0 \\
\hline Kardiatonika & 0 & 0 & 0 & 0 & 0.277 & 0 & 0 \\
\hline lanatosida & 0 & 0 & 0 & 0 & 0.031 & 0.031 & 0 \\
\hline Digoksina & 0 & 0 & 0 & 0 & 0 & 0.277 & 0 \\
\hline Isolasi & 0 & 0 & 0 & 0 & 0 & 0.277 & 0 \\
\hline Dammar & 0 & 0 & 0 & 0 & 0 & 0 & 0.277 \\
\hline Hidrat & 0 & 0 & 0 & 0 & 0 & 0 & 0.277 \\
\hline Arang & 0 & 0 & 0 & 0 & 0 & 0 & 0.277 \\
\hline Alkari & 0 & 0 & 0 & 0 & 0 & 0 & 0.277 \\
\hline SUM & 0.05 & 0.05 & 0.05 & 0.05 & 1.497 & 0.666 & 1.158 \\
\hline
\end{tabular}

\subsection{Pencarian Data}

Pencarian data pada aplikasi dengan cara menginputkan kata yang akan dicari, misalnya akan dicari kata glukosa, maka akan muncul beberapa data tumbuhan yang mempunyai unsur kata 'Glukosa' seperti ditunjukan pada Gambar 3.
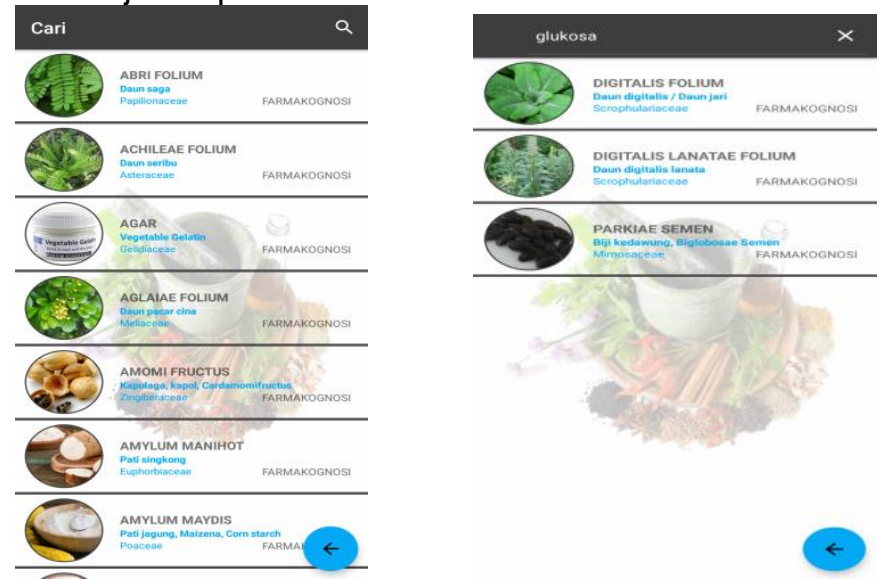

Gambar 3. Contoh pencarian kata 'Glukosa' pada kamus digital

Hasil yang ditunjukkan pada Gambar 3 adalah proses memfilter data tanaman obat yang mengandung unsur kata yang dicari, dalam contoh ini kata 'Glukosa yang diinputkan dalam kamus digital menampilkan sebanyak tiga data tanaman obat yaitu tanaman obat Digitalis Folium, Digitalis Lanatae Folium, dan Parkiae Semen. Khasiat dan detail dari tanaman obat bisa ditampilkan dalam kamus digital seperti ditunjukkan pada Gambar 4. Hasil akurasi pencarian kata menggunakan algoritma Rochio mencapai 100 persen berdasarkan pengujian pada setiap kata yang diinput, kata yang diinput bisa muncul di semua field selama kata yang dicari memang ada dalam database.
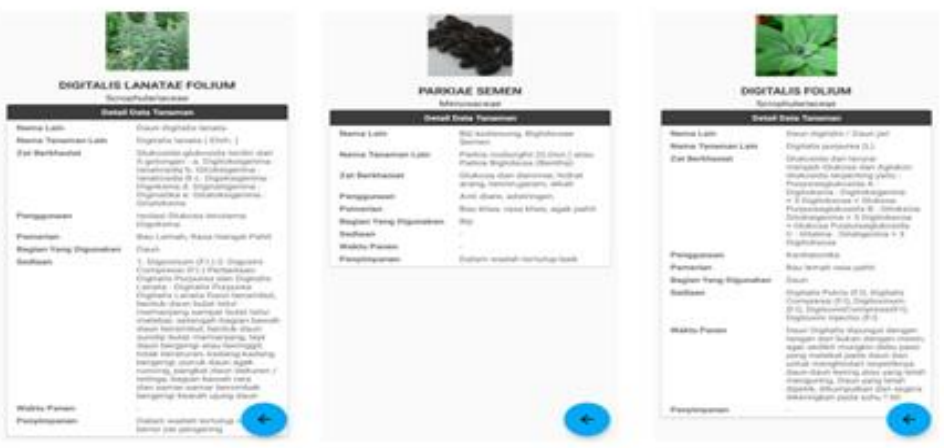

Gambar 4 Detail Data Tanaman 


\section{Kesimpulan}

Kesimpulan dari penerapan algoritma Rocchio untuk pencarian data tanaman obat dapat memudahkan pengguna dalam mencari detail tentang nama daerah tanaman, khasiat, cara meracik, serta bagian tanaman yang dapat digunakan untuk mengobati penyakit tanpa harus membaca satu per satu data seperti data yang tertulis dalam buku atau kamus manual tanaman obat. Aplikasi dibuat menggunakan android yang memungkinkan pengguna bisa menginstall di dalam perangkat mobile yang bisa digunakan secara realtime dengan menginputkan kata kunci sesuai dengan kebutuhan pengguna.

\section{Referensi}

[1] IPB Magazine. 2015.

http://ipbmag.ipb.ac.id/orasiilmiah/ c310cca1b6c979754e8d90b8f187b8d9/Guru-Besar-IPB-Tahun 2050-Nilai-Tanaman-ObatMencapai-Lima-Triliun-Dolar. IPB Press. Bogor

[2] Harsani P, Qurania A, Triastinuriatiningsih. 2014. Pengembangan Web Services Identifikasi Tanaman menggunakan Kode Fraktal dalam Sistem Informasi Tanaman Obat Indonesia. Proceeding Seminar Nasional Teknologi Informasi Komunikas dan Manajemen. Palembang.

[3] Harsani P, Mulyana, M, Prasetyorini. 2012. Application of Image Retrieval Using Fractal Dimension ti Identify Medicinal Plant. Proceeding Internasional Seminar on Science Technology Innovations 2012. ISBN 1978-602-95064-5-7.

[4] Najib. 2018. Similaritas Dokumen Tugas Akhir Menggunakan Metode Rocchio.

[5] Kristanda 2017. Rancang Bangun Aplikasi UMN Library Catalog Menggunakan Metode Rocchio Relevance Feedback.

[6] Hariana, A. 2008. Tumbuhan Obat dan Khasiatnya, Penebar Swadaya, Jakarta.

[7] Peraturan Menteri Kesehatan Republik Indonesia Nomor 6 tahun 2016 tentang Formularium Obat Herbal Asli Indonesia.

[8] Herdiani, E. (2012). Potensi Tanaman Obat Indonesia. Online. Tersedia: http://www.bbpplembang.info/index.php/arsip/artikel-pertanian/585-potensitanaman-obat-indonesia.

[9] Hidayat, S dan Team Flora. 2008. "Khasiat Herbal". Gramedia Jakarta

[10] Harfatiani, Rina Rizky. 2007. Teknik Riset Operasi. Surabaya: Kartika. Hal. 37.

[11] Selberg, E. W., "Information Retrieval Advances Using Relevances Feedback". Department of Computer Science and Engineering University of Washington, 2011.

[12] Liddy, E. D., "Automatic Document Retrieval. Encylopedia of Language and Linguistic. 2nd Ed". 2011. Philadelphia.

[13] Yugianus, P., Dachlan, H. S., dan Hasanah, R. N. 2013. Pengembangan Sistem Penelurusan Katalog Perpustakaan dengan Metode Rocchio Relevance Feedback. Jurnal Electrics Communications Controls Informatics Systems (EECCIS). Vol. 7 No. 1.

[14] Uden dan Mark, V., "Rocchio Relevance Feedback in Learning Classification Algorithms". Department of Computing Science University of Nijmegen. 2011. 